\title{
Análise de Impactos Ambientais Gerados nas Temporadas de Feriados da Praia dos Buritis em Palmas (TO)
}

\author{
Analysis of environmental impacts generated in the \\ Seasons of holidays from Praia dos Buritis in Palmas (TO, \\ Brasil)
}

Alana Cristina Moreira de Santana, Mary Lúcia Gomes Silveira de Senna

\begin{abstract}
RESUMO: O desenvolvimento sustentável é muito importante para a existência da vida no planeta. O uso de qualquer espaço sem planejamento pode causar impactos ao meio ambiente, que dependendo da proporção pode ser irreversível. A praia dos Buritis é muito frequentada por visitantes, mas não dispõe de informações sobre o uso e não apresenta infraestrutura suficiente para colaborar com a preservação do meio ambiente. Diante disso, o objetivo desse estudo foi adaptar uma lista controle simples de impactos ambientais em praias de rios, para assim, identificar os impactos ambientais gerados nas temporadas pós-feriados da praia dos Buritis e caracterizar a praia quanto a infraestrutura. Os feriados que realizou as análises foram os nacionais do segundo semestre de 2017 , bem como o feriado da confraternização universal de 2018. Os resultados mostram que a praia precisa de investimentos em sua infraestrutura e de campanhas educativas para minimizar impactos ambientais causados pela ação antrópica.
\end{abstract}

PALAVRAS-CHAVE: Impactos Ambientais; Desenvolvimento Sustentável; Praia dos Buritis.

\section{ABSTRACT}

Sustainable development is very important for the existence of life on the planet. The use of any space withot planning can cause impacts to the environment, which depending on the proportion may be irreversible. Buritis beach is very frequented by visitors, but it has no information on use and does not have enough infrastructure to collaborate with the preservation the environment. Therefore, the objective of this study was to adapt a simple control list of environmental impacts in river beaches, in order to identify the environmental impacts generated in the post-holiday seasons of Buritis beach and to characterize the beach in terms of infrastructure. The holidays that carried out the analyzes were the nationals of the second half of 2017 , as well as the universal fraternization holiday of 2018 . The results show that the beach needs investments in its infrastructure and educational campaigns to minimize environmental impactos caused by anthropic action.

KEYWORDS: Environmental Impacts; Sustainable Development; Buritis Beach. 


\section{Introdução}

Muito tem-se discutido sobre as ações a serem tomadas para alcançar o tão sonhado desenvolvimento sustentável. Sabe-se que a qualidade de vida das gerações vindouras depende das ações da presente geração para que não haja o seu comprometimento.

O conceito de desenvolvimento sustentável foi difundido e conhecido mundialmente, através de Brundtland em 1987 no relatório Our Common Future e publicado na World Comission on Environment and Development (WCED), que definiu desenvolvimento sustentável como o processo que permite satisfazer as necessidades da população atual sem comprometer a capacidade de atender às gerações futuras (MUNCK; BORIM-DE-SOUZA, 2013).

O turismo é uma ferramenta de desenvolvimento econômico, social e cultural importante para uma região. Por outro lado, possui muitos intervenientes ligados a essa indústria. Dessa forma, ele pode apresentar impactos positivos e negativos irreversíveis (SENNA, 2016).

Para que ocorra um desenvolvimento sustentável do ponto de vista econômico, é necessário respeitar a capacidade de carga dos ecossistemas, além de respeitar todos os limites da natureza que está sendo contemplada. Paralelamente, no plano social, o desenvolvimento sustentável deve preocupar-se em promover a coesão e a mobilidade social, além de elevar a participação política dos cidadãos e respeitar suas culturas. Sendo que a prática e concepções vigentes, são fundamentais para que isso ocorra, integrando-se valores econômicos e ambientais (MATTOS, et al., 2005).

Oliveira et al. (2014), afirma que o meio ambiente sofreu impactos com o progresso tecnológico e científico. Por isso, é importante que repense essa conjuntura, sendo que os cidadãos devem ter uma alta conscientização que os recursos naturais são finitos e não renováveis.

O lago de Palmas é resultado de um represamento do rio Tocantins e que com isso surgiu as suas margens praias artificiais que tem um grande potencial turístico. Entre essas praias está a dos Buritis localizada na região sul de Palmas e recebe uma grande quantidade de turistas e visitantes durante 0 ano. Conforme pesquisas da SEDETUR (2015), as praias do estado do Tocantins tiveram um fluxo de visitantes em 2015 de 173.276, sendo $66,48 \%$ desse total, turistas.

Para a elaboração desse estudo, buscou-se adaptar uma lista de controle simples de impactos ambientais em praias de rios, para identificar impactos gerados após as temporadas pós-feriados, bem como, caracterizar a praia quanto a infraestrutura. 


\section{Metodologia}

O presente trabalho foi desenvolvido tendo como parâmetro as tipologias de pesquisa exploratória e descritiva.

De acordo com Selltiz et al. (1965, apud OLIVEIRA, 2011) enquadram-se na condição de estudos exploratórios todos aqueles que buscam descobrir informações, na tentativa de adquirir maior conhecimento com o fenômeno pesquisado. Eles possibilitam aumentar a erudição do pesquisador sobre os acontecimentos, permitindo a formulação mais precisa de problemas, criar novas teorias e realizar novas pesquisas mais estruturadas. Desse modo, o planejamento da pesquisa necessita ser compreendida o bastante para permitir a análise dos vários aspectos relacionados com o fenômeno. Tendo em vista o levantamento preliminar de informações do objeto de estudo por meio de pesquisa bibliográfica para tentar compreender o fenômeno, acredita-se que a pesquisa em questão se enquadra neste formato de pesquisa.

Da mesma forma, a pesquisa é considerada descritiva, pois foi feito um levantamento de dados da praia que foram analisados a priori. Segundo Aaker, Kumar e Day (2004, apud Oliveira, 2011), a pesquisa descritiva, normalmente, usa informações dos levantamentos e caracteriza-se por teorias especulativas que não especificam relações de causalidade.

A proposta de pesquisa foi baseada nos estudos de Oliveira e Biazoto (2013) que utilizou a metodologia lista de controle simples para avaliar os impactos ambientais causados pelos aviários no Paraná. Então, foi feita uma adaptação da lista de controle apresentada pelos referidos autores, de modo que pôde contemplar os impactos ambientais de praias e em rios (Tabela 1).

Tabela 1: Lista de impactos ambientais.

Table 1: List of environmental impacts.

\begin{tabular}{|l|l|l|l|l|}
\hline \multicolumn{1}{|c|}{ Fator Ambiental } & IN & IP & ER & EI \\
\hline 1. Acúmulo de lixo & & & & \\
\hline 2. Alimentação de animais & & & & \\
\hline 3. Alteração do ar & & & & \\
\hline 4. Alteração do relevo & & & & \\
\hline 5. Comportamento (uso de som automotivo) & & & & \\
\hline 6. Contaminação do Solo & & & & \\
\hline 7. Destruição da Vegetação & & & & \\
\hline 8. Empreendimentos & & & & \\
\hline 9. Poluição da água & & & & \\
\hline 10. Poluição sonora & & & & \\
\hline 11. Lixo na areia & & & & \\
\hline 12. Banheiro (água) & & & & \\
\hline 13. Saneamento básico & & & & \\
\hline 14. Poluição visual & & & & \\
\hline
\end{tabular}

IN Impacto Negativo; IP Impacto Positivo; ER Efeito Reversível; El Efeito Irreversível Fonte: (OLIVEIRA; BIAZOTO, 2013 adaptado por SANTANA; SENNA). Source: (OLIVEIRA; BIAZOTO, 2013 adapted by SANTANA; SENNA). 
Na metodologia proposta, check-list (ou listagem), é feita uma lista de controle de ações e atividades previstas no local, que podem ser comparadas nas fases antes e depois do fenômeno (JOHNSON, 2012). Segundo o autor esta lista pode ser uma simples checagem de impactos ou podem ainda estabelecer um sistema de ponderação dos efeitos ambientais. Neste trabalho houve a classificação segundo os seguintes parâmetros: IN - Impacto Negativo; IP - Impacto Positivo; ER - Efeito reversível; El - Efeito Irreversível.

A avaliação foi realizada nos finais de semana que antecedeu as datas dos feriados nacionais do segundo semestre do ano de 2017, bem como nos finais de semana dos feriados. As saídas foram previamente definidas de acordo como mostra a Tabela 2.

Tabela 2: Saídas de avaliação dos impactos ambientais na praia.

Table 2: Outputs of the evaluation of environmental impacts on the beach.

\begin{tabular}{|c|c|c|c|}
\hline Nome do Feriado & Dia / mês / ano & Antes & Após \\
\hline $\begin{array}{c}\text { Dia das Crianças e dia de } \\
\text { Nossa Senhora de Aparecida }\end{array}$ & 12 de outubro de 2017 & Sim & Sim \\
\hline Proclamação da República & 15 de novembro de 2017 & Não & Sim \\
\hline Confraternização Universal & 01 de janeiro de 2018 & Não & Sim \\
\hline
\end{tabular}

\section{Desenvolvimento Sustentável e o Turismo}

A proposta de um desenvolvimento sustentável passa a ser discutida em todas as atividades econômicas em desenvolvimento, inclusive no turismo, que a partir de sua consolidação mundial, vem causando efeitos positivos na economia e em atividades sociais. Com todos esses benefícios, surgiram também os efeitos negativos dessa atividade, impactando diretamente a natureza dos lugares visitados (DUTRA, 2016).

No turismo, o planejamento e estudos é uma ação fundamental para a iniciação de qualquer atividade ligada ao meio, para que as comunidades receptoras não venham sofrer com os impactos negativos causados pela atividade, sem antes ter ocorrido o planejamento.

O planejamento turístico pode ser analisado de um lado como o conjunto de atividades previamente concebidas com o objetivo de promover o atendimento das necessidades de consumo dos visitantes, do outro lado, a comunidade receptora, é concebida com benefícios econômicos e sociais decorrentes do intercâmbio cultural (CARVALHO, 2010).

O planejamento turístico envolve um processo contínuo de tomada de decisões mediante a análise da realidade local, em termos de potencialidades e projeção de cenários. (CARVALHO, 2010).

Os recursos naturais são insumos para o Turismo. Dessa forma, o desenvolvimento sustentável precisa de apoio, colaboração e compreensão das esferas públicas e privadas e de toda a comunidade em geral para 
utilizar esses recursos da forma correta, para que não haja impactos graves, que sejam irreversíveis. Nery et al. (2015) confirmam que a comunidade deve apoiar o desenvolvimento sustentável na tomada de decisões da sua região, e é necessário que tenha a colaboração entre o Poder Público e o Setor privado.

Dito isso, é evidente que o uso de recursos naturais sem um devido planejamento pode trazer múltiplos problemas como a poluição sonora, poluição do visual, poluição do solo e outro. Assim, no contrário, um planejamento pode trazer muitos benefícios, como por exemplo, na economia, e o uso consciente no presente preservará para as gerações futuras (SENNA, 2016).

\section{Lista de Controle Simples}

Sabe-se que há inúmeras metodologias capazes de monitorar impactos ambientais em regiões turísticas, tais como: AD HOC, Método Checklist, Matrizes de Interação, Redes de Interações, Superposição de Cartas, Modelos de Simulação, Metodologias Quantitativas e AMBITEC AGRO (CREMONEZ et al., 2014).

As Listas de Controle Simples é uma ferramenta de utilização simplificada capaz de avaliar os impactos para que ações corretivas possam ser aplicadas. Contêm uma enumeração de fatores que variam com o impacto ambiental, uma lista de características da ação que vão impactar, ou ambas. Desta forma, durante as análises, permite que não seja esquecido nenhum fator ( $\mathrm{FINUCCl,} \mathrm{2010).}$

As principais vantagens deste método é a facilidade de discernimento, rápida utilização na avaliação qualitativa de impactos primordiais, além de ser um bom método para fixação de prioridades e ordenação de informações e escolha de locais (MEDEIROS, 2010).

Já as desvantagens é que ele não identifica impactos diretos e indiretos, não consideram características temporais e espaciais, não examinam a relação entre impactos ambientais, não unem a ação ao impacto, raramente indicam a grandeza dos impactos e seus resultados são subjetivos (SUREHMA/GTZ, 1992, p. 12 apud STAMM, 2003).

Apesar de ser muito conhecida por órgãos ambientais esta metodologia sempre sofrem alterações ou passa por modificações antes de sua utilização. Isto acontece por razão de cada tipo de análise se fazer novos estudos para a confecção de novas listas individualizadas (FINUCCI, 2010). Mas apesar das desvantagens, acredita-se que ainda é muito utilizada no meio acadêmico por ser de fácil aplicação e apontamento imediato de áreas prioritárias para ação ambiental educativa. 


\section{Educação Ambiental}

Conforme a Lei $N^{\circ}$ 9.795, de 27 de abril de 1999, que consta no art. $1^{\circ}$, a educação ambiental é entendida, da seguinte forma:

Art $1^{\circ}$ Entendem-se por educação ambiental os processos por meio dos quais o indivíduo e a coletividade constroem valores sociais, conhecimentos, habilidades, atitudes e competências voltadas para a conservação do meio ambiente, bem de uso comum do povo, essencial à sadia qualidade de vida e sua sustentabilidade.

O objetivo da educação ambiental é formar indivíduos, despertando neles interesses ecológicos, que venham prevenir problemas ambientais e que contribuam para a preservação e conservação da natureza, respeitando todos os seus limites. Esse ensino deve ser obrigatório desde a pré-escola, passando pelos outros níveis educacionais, até os cursos superiores (SILVA JUNIOR, 2007).

A Lei № 9.795, de 27 de abril de 1999, no art. 5 (BRASIL, 1999), ainda apresenta os objetivos fundamentais da educação ambiental, e são:

I - o desenvolvimento de uma compreensão integrada do meio ambiente em suas múltiplas e complexas relações, envolvendo aspectos ecológicos, psicológicos, legais, políticos, sociais, econômicos, científicos, culturais e éticos;

II - a garantia de democratização das informações ambientais;

III - o estímulo e o fortalecimento de uma consciência crítica sobre a problemática ambiental e social;

IV - o incentivo à participação individual e coletiva, permanente e responsável, na preservação do equilíbrio do meio ambiente, entendendo-se a defesa da qualidade ambiental como um valor inseparável do exercício da cidadania;

V - o estímulo à cooperação entre as diversas regiões do País, em níveis micro e macrorregionais, com vistas à construção de uma sociedade ambientalmente equilibrada, fundada nos princípios da liberdade, igualdade, solidariedade, democracia, justiça social, responsabilidade e sustentabilidade;

VI - o fomento e o fortalecimento da integração com a ciência e a tecnologia;

VII - o fortalecimento da cidadania, autodeterminação dos povos e solidariedade como fundamentos para o futuro da humanidade. 
Cuidar do meio ambiente é uma responsabilidade de todos e esses objetivos devem ser executados na prática, para que não haja a intensificação de impactos ambientais gravíssimos, decorrentes da ação humana.

De acordo com Guerreiro (2016) a educação ambiental nas escolas e fora dela, é uma alternativa para superar o quadro degradação e desconsideração ambiental. Dessa forma, haverá uma formação de indivíduos preocupados com a preservação ambiental e com a sustentabilidade, e assim, estará também praticando a sua cidadania.

\section{Praias Fluviais}

A água é um recurso natural muito importante para a existência humana, para o desenvolvimento econômico, para a qualidade de vida das populações humanas e para a sustentabilidade dos ciclos do planeta. De forma global, existe a baixa disponibilidade de água e divergências em algumas regiões, como no caso o Norte e Nordeste do Brasil, onde no Norte tem uma abundância de água e é menos habitado que o Nordeste que possui restrições hídricas (ALVES et al, 2012).

De acordo com a cartilha Turismo de Sol e Praia: orientações básicas (MTUR, 2010):

O Turismo de Sol e Praia está diretamente associado à água e seus espaços imediatos, como os principais recursos turísticos e de lazer. No entanto, seus espaços ultrapassam o segmento de Sol e Praia e associam-se também a atividades náuticas, de pesca, de aventura, de ecoturismo, entre outras.

Nos países de clima favorável a utilização das águas torna-se uma atividade de lazer. E essa prática ocorre em lugares onde há uma abundância de recursos hídricos, onde as condições são propícias para a prática de atividades recreativas (LOPES, SPERLING; MAGALHÃES Jr, 2015).

O Tocantins tem perfil turístico voltado para sol e praia, onde todo ano os municípios se preparam para a temporada de praia que dura aproximadamente um mês, sendo que em alguns municípios a estimativa de públicos é maior do que a população, e isso faz gerar impactos ambientais negativos e positivos (SEDETUR, 2008).

As "praias fluviais" localizadas em ambientes ribeirinhos, onde haja um aglomerado de pessoas no mesmo espaço, faz-se necessário direcionar esforços no sentido de compreender, em base científica, sendo que essa prática é bastante impactante ao ambiente e ao turismo (BRITO et al., 2002).

As praias, nos rios Tocantins e Araguaia, acontecem no momento de suas baixas, assim, formam os bancos de areia. As praias surgem durante o período onde na maioria do país o clima é frio ou chove, sendo que no 
Tocantins faz muito sol. Desta forma, atrai milhares de visitantes durante todo o ano, mas especialmente nas temporadas de praia e feriados (SEDETUR, 2015).

Segundo o MTUR (2010) o segmento turismo de sol e praia é concebido com atividades ligadas a lazer, entretenimento ou descanso em praias, em função da presença de sol, água e calor.

Segundo a cartilha Turismo de Sol e Praia: orientações básicas (MTUR, 2010):

A formação das praias fluviais e lacustres está intimamente relacionada ao transporte e tipo de sedimentos trazidos pelos rios e aos períodos de cheias e de estiagens. Com as cheias, as praias podem desaparecer e, na estiagem, podem se tornar bem extensas e propícias para o turismo, recreação e lazer.

E é neste contexto que buscou-se estudar a capital do Tocantins, Palmas. O lago da capital foi criado, após a construção da Usina Hidrelétrica Luís Eduardo Magalhães. A extensão do lago é de $172 \mathrm{~km}$, sendo só em Palmas são 54 km de comprimento (G1 TOCANTINS, 2015). Com a formação do lago, foram aos poucos surgindo praias no entorno da capital, como a praia dos Buritis (Figura 1).

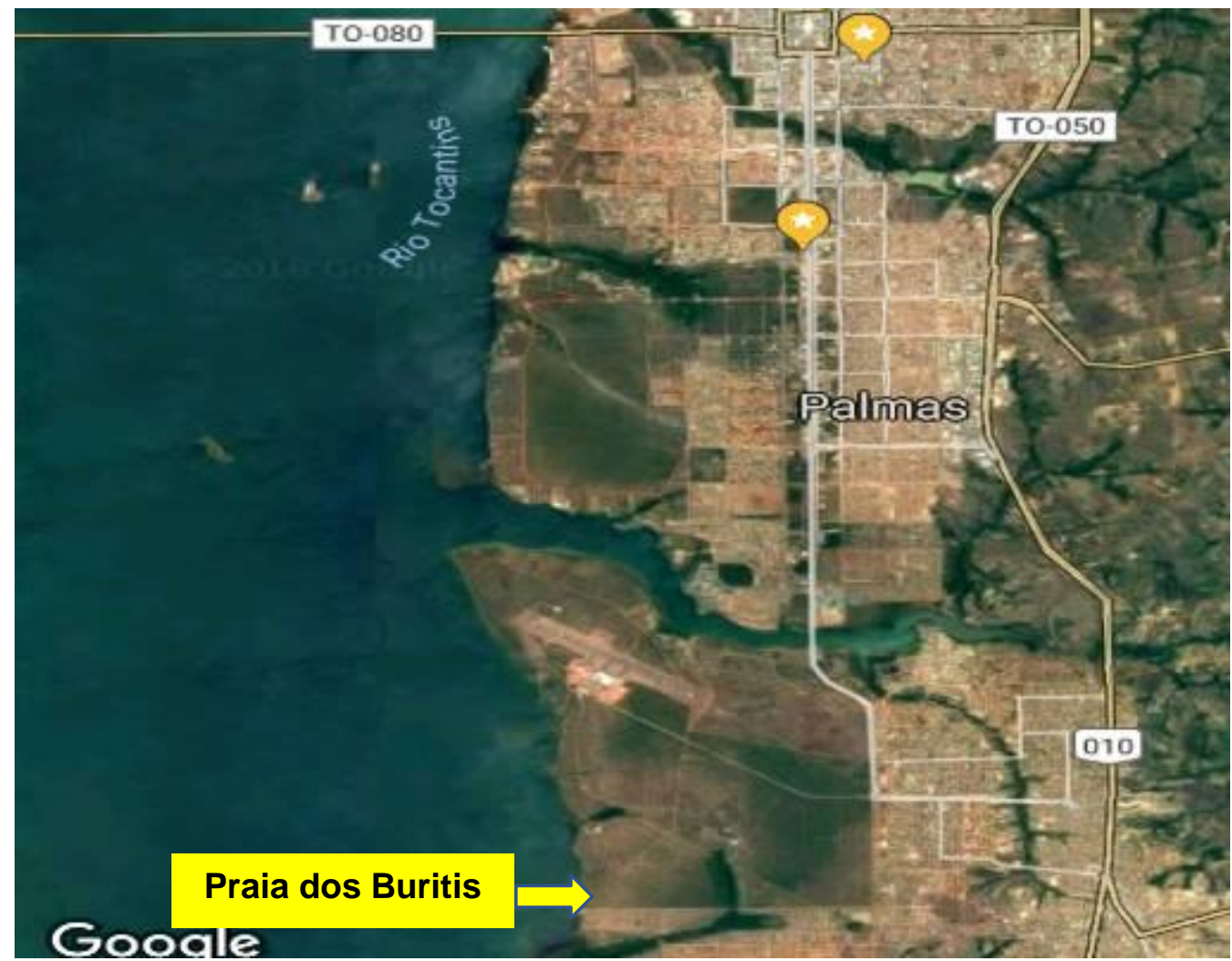

Figura 1: Mapa com localização da praia estudadas. Fonte: Google maps.

Figure 1: Location map with the beaches studied. Source: Google maps. 


\section{Resultados e Discussões}

A primeira análise foi feita antes do feriado do Dia das Crianças e de Nossa Senhora de Aparecida. A praia tem infraestrutura mal acabada, como banheiros em péssimo estado de uso, estacionamento sem demarcação, não há lixeiras públicas, e ainda não tem fornecimento de energia elétrica, os equipamentos do restaurante da praia, funcionam através de energia de gerador movido à gasolina. O lixo é jogado em um recipiente improvisado pelo dono do único empreendimento que há no local.

A praia, não dispõe de placas informativas sobre o uso e nem telas de proteção contra-ataques de piranhas e de outros animais, para mais, existe um cheiro ruim no local. Inclusive, observou- se também carcaça de peixe morto.

Atrativos turísticos devem ter infraestrutura adequada para atender os turistas e visitantes, para que não gere impactos negativos. Sabe-se que a infraestrutura em boas condições de uso, faz parte do desenvolvimento sustentável. Antes que ocorra a atividade turística é importante que haja planejamento.

O planejamento turístico é multidisciplinar. Para que tenha um bom resultado é necessária a união de vários segmentos, não ligados apenas ao turismo. A primeira alternativa é inserir a comunidade no processo, para mais, a infraestrutura básica deve acontecer antes da infraestrutura turística e do consentimento das esferas públicas (BRITO; SÁ, 2014).

Um funcionário do único empreendimento da praia informou que a coleta de lixo ocorre aos sábados, aos domingos e nas segundas por ser estes os dias de maior visitação.

Na praia existe banheiro, mas não tem torneiras com água nas pias para lavar as mãos (Figura 2) e nem portas de abrir e fechar com trinco, o que existe é uma cortina de pano, colocada improvisada no lugar da porta, além do mais, não existe uma repartição dos vasos sanitários (Figuras 3 e 4), o que se vê é urina de pessoas por todo o chão. Esta condição pode levar as pessoas a procurarem os rios para fazerem suas necessidades fisiológicas e/ou lavar as mãos após se alimentarem.

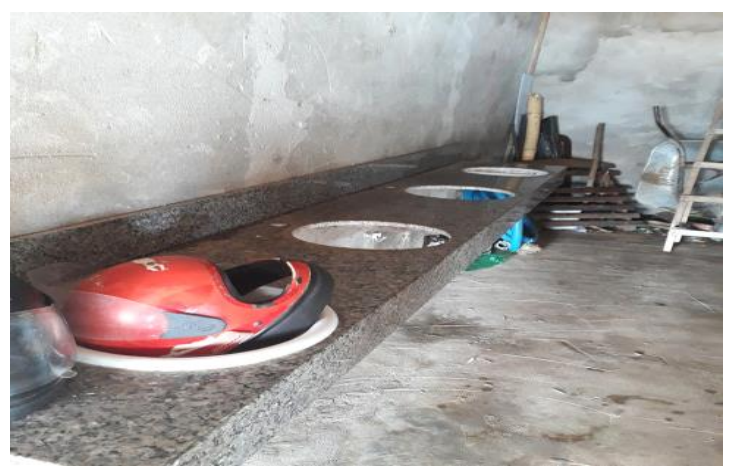

Figura 2: Pias do banheiro da praia dos Buritis que não funciona.

Figure 2: Buritis beach bathroom sinks not working.

Fonte: Dados da pesquisa.

Source: Research Data. 

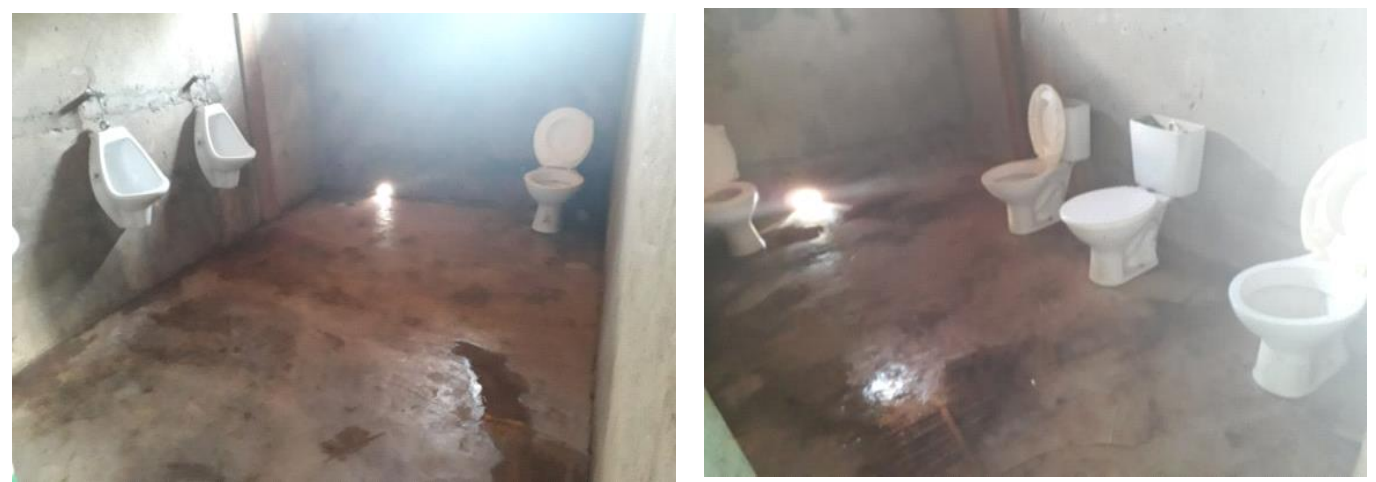

Figuras 3 e 4: Banheiro masculino do lado esquerdo e do lado direito banheiro feminino em péssimo estado de uso. Fonte: Dados da pesquisa.

Figures 3 e 4: Male bathroom on the left side and the right bathroom female in very poor state of use. Source: Research data.

O acesso a essa praia é por meio de condução própria, ou por meio de outros tipos de locomoção, como táxis, moto táxis, uber, entre outros. A prefeitura só disponibiliza ônibus até a praia no mês de julho, pois acontece a temporada de praia.

É possível ver na praia, que alguns usuários jogam seu próprio lixo em qualquer lugar (Figuras 5 e 6), sendo que essa atitude pode impactar ainda mais o ambiente.
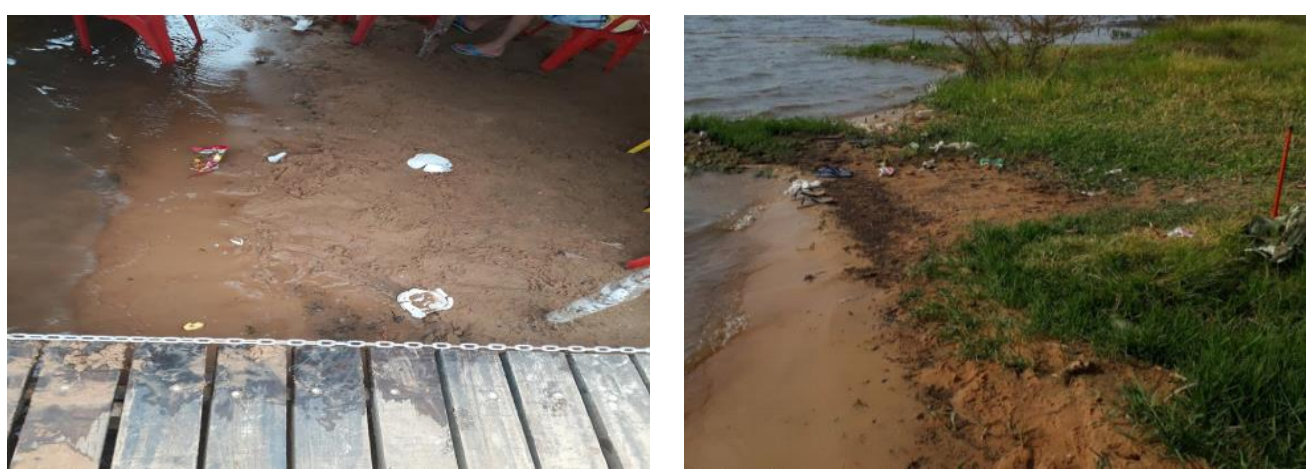

Figuras 5 e 6: Lixo na praia dos Buritis. Fonte: Dados da pesquisa. Figures 5 e 6: Trash on Buritis beach. Source: Research data.

Algumas partes da água dessa praia é muito suja e apresenta um odor ruim, o que se torna desagradável a quem a visita (Figura 7). Ainda é possível ver que algumas pessoas jogam carcaça de peixe em qualquer lugar da praia. Isso faz o local apresentar mau cheiro e podendo ser vetores de doenças. 


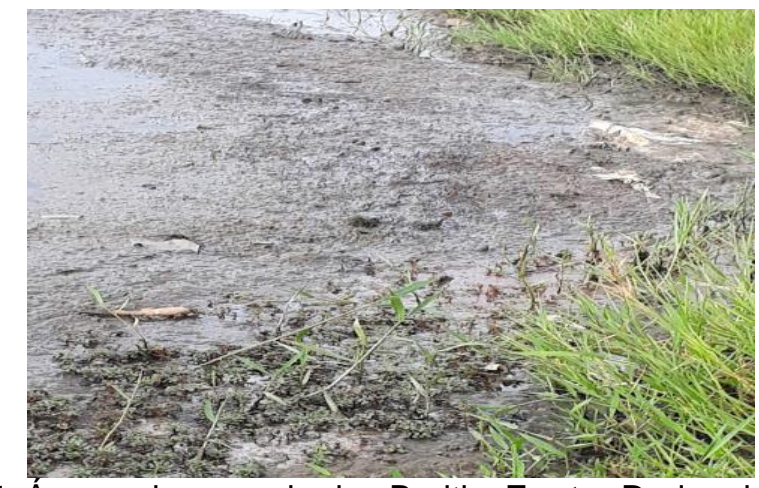

Figura 7: Água suja na praia dos Buritis. Fonte: Dados da pesquisa.

Figure 7: Dirty water on Buritis beach. Source: Research data.

$\mathrm{Na}$ segunda análise, realizada após o feriado de 12 de outubro, notou-se a presença de animais domésticos na área da praia. Esses animais ocasionam dejetos na areia e isso pode acarretar doenças as pessoas e aos próprios animais. Boukay (2005, apud Oliveira, 2011) associou a presença de animais domésticos nas praias com o aumento dos níveis de poluição da areia, em consequência de doenças transmitidas para humanos a partir de urinas e fezes parasitadas. As doenças que podem ser transmitas pelos animais é larva migrans cutânea (LMC), larva migrans visceral (LMV), toxoplasmose, leptospirose e verminoses.

O funcionário do único empreendimento da praia informou que as pessoas vão até lá e levam seus animais de estimação junto e que é comum a presença deles no local.

Um problema averiguado até o momento em todas as análises é o lixo esparramado por toda parte. Mas vale evidenciar que na praia não há lixeiras suficientes e nem placas informativas sobre o uso e tão pouco foi observado à presença de um fiscal nessa praia. Mas pode ver também que os mesmos problemas se repetem em todas as análises.

Campanhas educativas são muito importantes para o meio ambiente, uma vez que os impactos ambientais sempre se agravam e que pode ocasionar prejuízos a economia de um determinado lugar, a saúde humana, e ao ecossistema.

Voluntários da ONG Ecomov, fizeram em março de 2017, na praia do Itararé, em São Vicente, no litoral de São Paulo, uma campanha de conscientização sobre a poluição nas praias. Eles conversaram com banhistas, orientando-os a não jogar o lixo em qualquer parte da praia e fizeram coleta de lixo que avistaram. Ainda, fixaram cruzes para representar animais mortos (G1, SANTOS; REGIÃO, 2017).

$\mathrm{Na}$ terceira análise, realizada após o feriado da Proclamação da República, percebeu-se que os impactos notados anteriormente, prevaleceram até o momento dessa averiguação. O lixo na área da praia continua sendo um dos problemas que se repete sempre (Figura 8). Ainda foi presenciado shows com o volume alto, emitido pela caixa de som. 


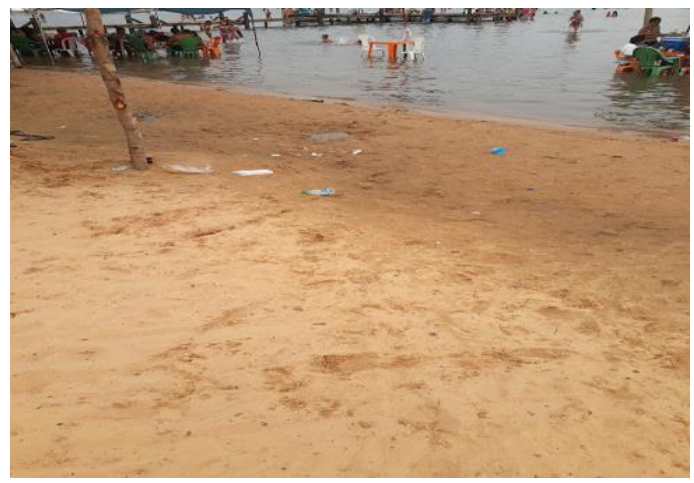

Figura 8: Lixo na praia dos Buritis visto na terceira análise. Fonte: Dados da pesquisa. Figure 8: Trash on Buritis beach seen in the third analysis. . Source: Research data.

No dia dessa análise, foi notado que pessoas se alimentaram em cima do píer da praia e não tiveram a preocupação em jogar o resto da comida no lugar certo, deixaram no mesmo lugar que comeram (Figura 9). Isto pode acarretar a queda do alimento na água e o risco de atrair animais para se alimentar, como já relatado anteriormente.

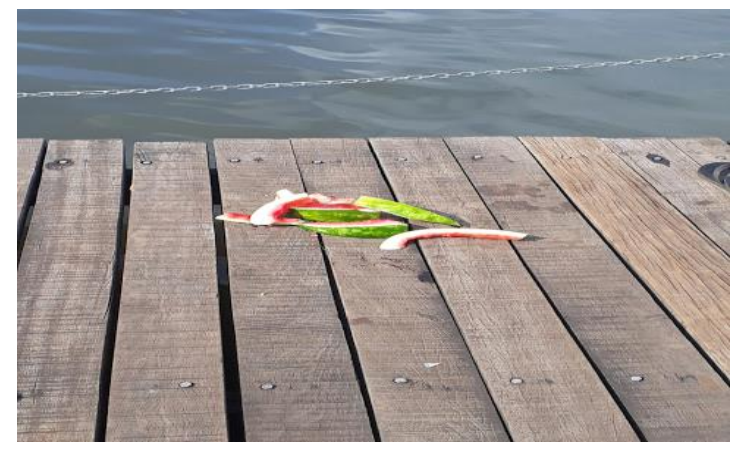

Figura 9: Resto de comida deixado em cima do píer. Fonte: Dados da pesquisa.

Figure 9: Rest of food left on the pier. Source: Research data.

De acordo com Guerreiro (2016) o consumo de comida em locais onde há animais provoca impactos negativos, pois a fauna é atraída por restos de comidas, e até mesmo por resíduos que não são orgânicos, como sacolas, latas, garrafas, sendo que esses objetos podem machucá-los e até mesmo matá-los.

A última análise na praia dos Buritis aconteceu após o feriado da Confraternização Universal. Na análise foi visto pescadores colocando rede de pesca no lago (Figura 10), ainda assim, como em todas as análises foi possível ver novamente lixo em sua área. Outros problemas vistos anteriormente continuaram como a falta de placas informativas sobre o uso, falta de telas de segurança para evitar ataques de animais, bem como a falta de lixeiras públicas. 


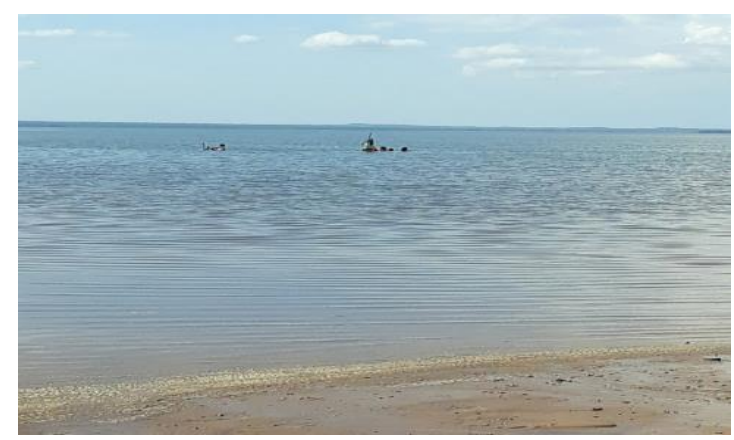

Figura 10: pescadores pondo rede na praia dos Buritis. Fonte: Dados da pesquisa.

Figure 10: Fishermen laying net on Buritis beach. Source: Research data.

$\mathrm{Na}$ Tabela 3 está exemplificado por " $\mathrm{x}$ " os impactos que apareceram nas quatro saídas. O xis marcado nos espaços representa a quantidade de vezes que o impacto apareceu nas análises.

Tabela 3: Análise dos impactos nas 4 (quatro) saídas na praia dos Buritis.

Table 3: Analysis of the impacts in the four (4) exits on the Buritis beach.

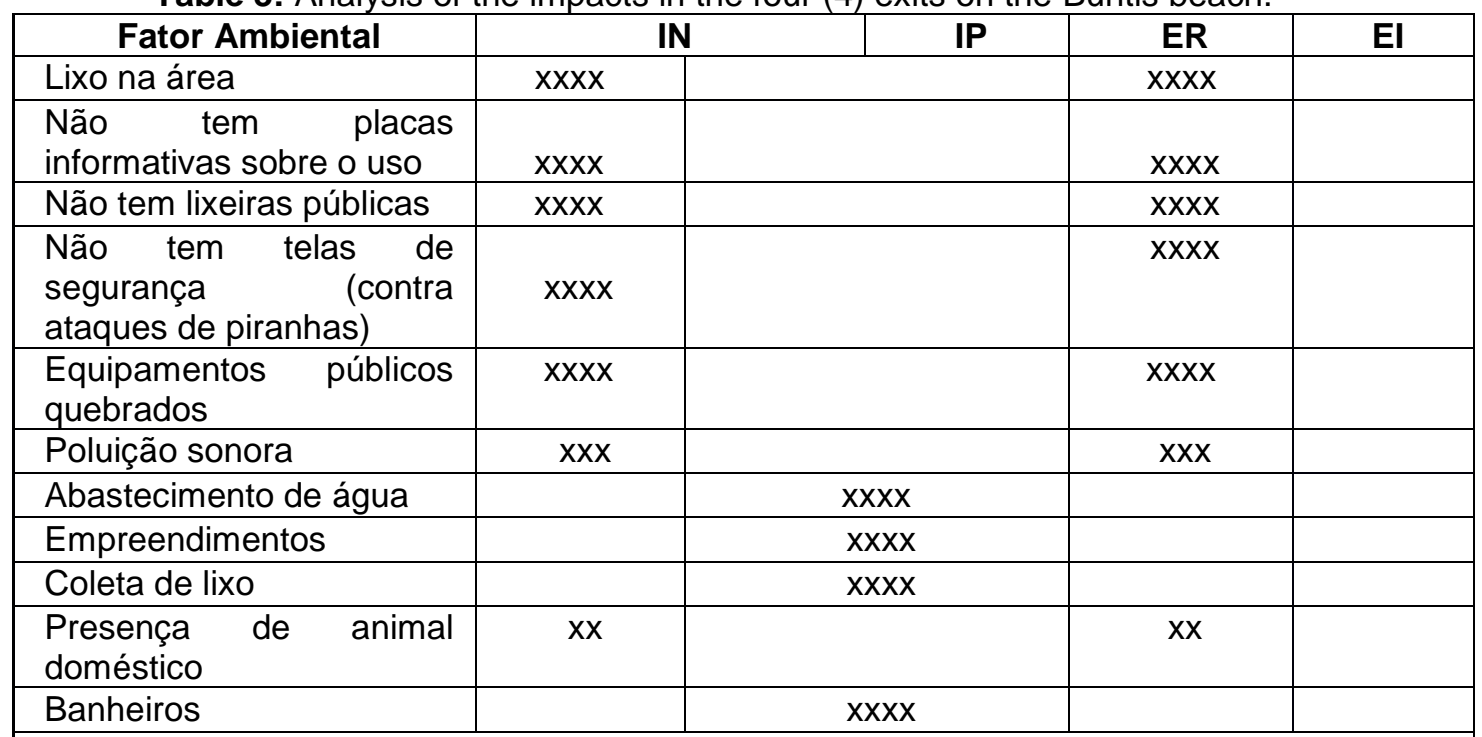

IN Impacto Negativo; IP Impacto Positivo; ER Efeito Reversível; El Efeito Irreversível Fonte: (OLIVEIRA; BIAZOTO, 2013 adaptado por SANTANA; SENNA). Source: (OLIVEIRA; BIAZOTO, 2013 adapted by SANTANA; SENNA).

Nesta praia os impactos negativos notificados foram: lixos na área, falta de placas informativas sobre o uso, equipamentos públicos quebrados, falta de lixeiras, falta de telas de segurança contra-ataques de piranhas, poluição sonora e presença de cachorros. Percebeu-se que houveram duas saídas que mais geraram impactos negativos: 12 de outubro e 15 de novembro, desta forma, deveriam intensificar as ações de prevenção de redução dos impactos ambientais com ações de educação ambiental nestes períodos. 


\section{Considerações Finais}

O presente estudo teve como objetivo analisar os impactos ambientais gerados nas temporadas pós-feriados da praia dos Buritis. Sua principal finalidade é avaliar a necessidade de proposição de ações de educação ambiental na praia estudada.

Essa praia sofre com impactos ambientais negativos. Dessa forma, precisa haver mais fiscalização para minimizar com os impactos ambientais do lugar. Uma boa infraestrutura é muito importante para um ambiente não sofrer com tantos impactos, mas essa praia carece de infraestrutura básica para atender turistas e visitantes. Assim, se os impactos não forem solucionados pode ocorrer dessa praia não ter mais visitações e resultar em seu fechamento e consequentemente quem trabalha na praia serão os maiores prejudicados.

Além do mais, há a necessidade de investir em educação ambiental para alertar ainda mais a população sobre os problemas ambientais que 0 meio ambiente vem sofrendo.

Acredita-se que o método lista de controle simples, adaptado dos estudos de Oliveira e Biazato (2013), foi o mais adequado neste estudo para analisar os impactos ambientais na Praia dos Buritis. O método apresentou-se como uma ferramenta simplificada que diagnostica bem os impactos ambientais em praias fluviais. Sabe-se que cada ambiente natural apresenta problemas diferentes ou iguais a de outros lugares para serem solucionados. Desta forma, a listagem torna-se um meio para levantar informações e dados para que possam ser analisados, e assim, os problemas identificados venham ser discutidos e propostos melhorias para atrativos naturais.

\section{Referências bibliográficas}

ALVES, T. L. B.; LIMA, V. L. A.; FARIAS, A. A. Impactos ambientais no rio paraíba na área do município de Caraúbas - PB: região contemplada pela integração com a bacia hidrográfica do rio São Francisco. Caminhos de Geografia, [S.I.], v. 13, n. 43, out. 2012. ISSN 1678-6343. Disponível em: <HTTP://WWW.SEER.UFU.BR/INDEX.PHP/CAMINHOSDEGEOGRAFIA/ ARTICLE/VIEW/16758/10524 >. Acesso em: 08 set. 2017.

BRASIL. LEI No 9.795, DE 27 DE ABRIL DE 1999. Dispõe sobre a educação ambiental, institui a Política Nacional de Educação Ambiental e dá outras providências. Diário Oficial da União, Brasília, 24 de abr. de1999.

BRITO, C.M.O.; SÁ, H.S.F. Planejamento turístico: estudo de caso da cidade de Belém (PA). Revista Brasileira de Ecoturismo, São Paulo, v. 7, n.1, 2014, pp. 138-150.

BRITO, E. R. et al. Perfil ambiental denominado praias "praias fluviais", Estado do Tocantins. Viçosa, MG: Revista Árvore, v 26, n. 3, p 349-355, 2002. 
CARVALHO, K. D. Lugar de memória e turismo cultural: apontamento teóricos para o planejamento urbano sustentável. Revista de Cultura, v. 4, n. 1, 2010.

CREMONEZ, F. E. CREMONEZ, P. A, FEROLDI, M. CAMARGO, M.P., KLAJN, F.F. FEIDEN, A. Avaliação de impacto ambiental: metodologias aplicadas no Brasil. Revistas de Monografias Ambientais, v. 13, n.5, , dez. 2014.

DUTRA, V. C. Monitoramento de indicadores-chave do turismo sustentável em unidades de conservação: um estudo de caso no parque estadual do Jalapão - Tocantins. Ipen - Autarquia Associada à Universidade de São Paulo, São Paulo, 2016.

FINUCCI, M. Metodologias utilizadas na avaliação do impacto ambiental para a liberação comercial do plantio de transgênicos - uma contribuição ao estado da arte no Brasil. Universidade de São Paulo. Faculdade de Saúde Pública, São Paulo, 2010.

GUERREIRO, N. S. Levantamento das atividades do ecoturismo de cachoeira na região de Caiapônia - GO e seus principais impactos ambientais. 2016. 94 f. Dissertação (Mestrado em Ciências da Saúde). Pontifícia Universidade Católica de Goiás, GOIÂNIA, 2016.

G1 SANTOS E REGIÃO. Voluntários fazem campanha contra o http://g1.globo.com/sp/santos-regiao/verao/2017/noticia/2017/03/voluntarios -fazem-campanha-sobre-descarte-de-lixo-nas-praias.html> Acesso em 25 de fevereiro de 2018.

G1 TOCANTINS. Pioneiros de Palmas relembram como era a Praia da Graciosa. Disponível em: <http://g1.globo.com/to/tocantins/noticia/2015/05/ pioneiros-de-palmas-relembram-como-era-praia-da-graciosa.html>. Acesso em 13 de setembro de 2017.

JOHNSON, A. B. Avaliação e gestão de impactos ambientais de infraestrutura hídrica em projetos de irrigação. TCC. Monografia de Conclusão de Curso - Universidade Federal do Rio Grande do Sul, Porto Alegre, 2012.

LOPES, F. A.; SPERLING, E. V.; MAGALHÃES JR, A. P. Indicadores para balneabilidade em águas doces no Brasil. Geografias. 2015, vol. 11, n 1.

MATTOS, K. M. C.; MATTOS, K. M. C.; MATTOS, A. Valoração econômica do meio ambiente dentro do contexto do desenvolvimento sustentável. Revista Gestão Industrial. 2005, v.1, n. 2, pp. 105 - 117. ISSN 1808 0448.

MEDEIROS, R. D. Proposta metodológica para avaliação de impacto ambiental aplicada a projetos de usinas de geração eólio-elétricas. Instituto de Pesquisas Tecnológicas do Estado de São Paulo, São Paulo, 2010. 
MTUR - Ministério do Turismo. Turismo de sol e praia: orientações básicas. / Ministério do Turismo, Secretaria Nacional de Políticas de Turismo, Departamento de Estruturação, Articulação e Ordenamento Turístico, Coordenação Geral de Segmentação. - Brasília: Ministério do Turismo, 2010.

MUNCK, L.; BORIM-DE-SOUZA.; R. Compreensão de desenvolvimento sustentável a partir do estabelecimento de tipos ideais. Organizações \& Sociedade - Salvador, v. 20, n. 67, p. 651-674, 2013.

NERY, C.; SOUZA, J.; TOMAZZONI, E. L. Análise do Plano de Turismo Municipal de São Paulo (PLATUM), com enfoque no desenvolvimento socioeconômico. REVISTA ACADÊMICA OBSERVATÓRIO DE INOVAÇÃO DO TURISMO, [S.I.], p. 19 - 54, abr. 2016. ISSN 1980-6965. Disponível em: <http://publicacoes.unigranrio.com.br/index.php/raoit/article/ view/3419/1563>. Acesso em: 09 set. 2017.

OLIVEIRA, E. S.; BIAZOTO, C. D. S. Avaliação dos impactos ambientais causados pelos aviários no município de Assis Chateaubriand, no oeste do estado do Paraná. Revista Verde de Agroeologia e Desenvolvimento Sustentável. Vol. 8, n. 2, 2013.

OLIVEIRA, G. F.; DINARTE, P. V.; SILVA, R. L. O direito de acesso À informação ambiental como potencializador da e-democracia: o papel do Governo Aberto na conscientização ambiental a partir do desenvolvimento de plataformas e aplicativos. Democracia Digital e Governo Eletrônico. Florianópolis, $\mathrm{n}^{\circ} 11$, p. 138-162, 2014.

OLIVEIRA, M. F. Metodologia cientifica: um manual para a realização de pesquisas em administração. Catalão, GO: Universidade Federal de Goiás, p. 20 e 22, 2011.

SEDETUR - SECRETARIA DE DESENVOLVIMENTO ECONÔMICO E TURISMO. Análise geral do perfil do público participante. Estado do Tocantins, 2015.

SENNA, M.L.G.S. A aplicabilidade do índice de qualidade de vida, da pegada ecológica do turismo e dos indicadores de sustentabilidade da organização das nações unidas para destinos turísticos de pequeno porte: um estudo de caso no jalapão - TO. Ipen - Autarquia Associada à Universidade de São Paulo, São Paulo, 2016.

SILVA JÚNIOR, I. S. A Educação Ambiental Como Meio para a Concretização do Desenvolvimento Sustentável. Direito Público, [S.I.], v. 4, n. 17, jan. 2010. ISSN 2236-1766.

STAMM, H. R. Método para avaliação de impacto ambiental (AIA) em projetos de grande porte: estudo de caso de uma usina termelétrica. Universidade Federal de Santa Catarina. Programa de Pós-Graduação em Engenharia Industrial, Florianópolis, 2003. 
Alana Cristina Moreira de Santana: Instituto Federal de Educação, Ciência e Tecnologia do Tocantins, Palmas, TO, Brasil.

E-mail: alanacristinasantana@gmail.com

Link para o currículo Lattes: http://lattes.cnpq.br/3366790258161250

Mary Lúcia Gomes Silveira de Senna: Instituto Federal de Educação, Ciência e Tecnologia do Tocantins, Palmas, TO, Brasil.

E-mail: marysenna@ifto.edu.br

Link para o currículo Lattes: http://lattes.cnpq.br/1745769805611202

Data de submissão: 25 de abril de 2018

Data de recebimento de correções: 13 de abril de 2019

Data do aceite: 13 de abril de 2019

Avaliado anonimamente 